\title{
Treatment Options for Proximal Humerus Fractures Associated with Shoulder Dislocation in Convulsive Disorders and Outcome Analysis Based on Everisto's (Ess) Proposed Scoring System
}

ISSN: 2576-8875

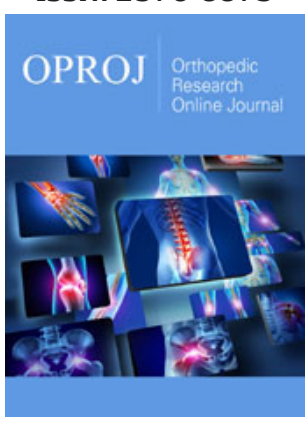

*Corresponding author: Everisto Opondo, Department of Surgery, Jomo Kenyatta University of Agriculture and Technology, Kenya

Submission: 战 February 03, 2020

Published: 傗February 10, 2020

Volume 6 - Issue 4

How to cite this article: Everisto Opondo. Treatment Options for Proximal Humerus Fractures Associated with Shoulder Dislocation in Convulsive Disorders and Outcome Analysis Based on Everisto's (Ess) Proposed Scoring System. Ortho Res Online J. 6(4). OPROJ.000645.2020. DOI: $10.31031 /$ OPROJ.2020.06.000645

Copyright@: Everisto Opondo, This article is distributed under the terms of the Creative Commons Attribution 4.0 International License, which permits unrestricted use and redistribution provided that the original author and source are credited.
Everisto Opondo*

Department of Surgery, Jomo Kenyatta University of Agriculture and Technology, Kenya

\begin{abstract}
Introduction: Fractures of proximal humerus associated with dislocations pose a challenge in clinical decision making and management. Open Reduction and Internal Fixation (ORIF) can be done by plating, Kirshner wires (K-wires) or cancellous screws. The Proximal humeral internal locking system (PHILOS) plate provides greater angular stability and better anchorage of screws in osteoporotic bone. Arthroscopic repair of the soft tissue defects and percutaneous fracture fixation using cannulated screws is an option. Surgery is known to result early joint mobilization and a good functional outcome.
\end{abstract}

Materials and Methods: This study was conducted from November 2015 and May 2019. Nine adult patients and one paediatric patient who sustained proximal humeral fracture dislocations after a convulsive episode were included. For the surgical treatment the delto-pectoral approach was used with the fracture being reduced and fixed with a PHILOS plate, cancellous screws or K-wires. The patients were evaluated for range of motion of the shoulder, features of clinical union and radiological union. Overall outcome was assessed using the Everisto Scoring System (ESS).

Results: Based on the ESS excellent results were recorded in 50\%, good result in 33\% and two patients had a poor outcome (20\%). The range of motion at first, second and third follow ups showed gradual increase in forward flexion, abduction, external rotation and internal rotation.

Conclusion: Surgery provides a high degree of angular and axial stability with excellent functional outcomes in young patients. The use of ESS describes the outcome of shoulder fracture dislocations better in terms of disability and the need for further interventions.

Keywords: Proximal humerus fracture-dislocation; ORIF, Outcomes; Everisto's scoring system (ESS).

\section{Introduction}

The shoulder joint is prone to dislocation due to its anatomical structure and its biomechanics, which allow an extensive range of movement. It is believed that, among the major joints of the human body, the shoulder suffers most dislocations, with an incidence of 8.2 to 23.9 per 100,000 inhabitants [1]. In analysis of all shoulder dislocations, $4 \%$ are posterior and only $1 \%$ are associated with fractures. Fractures of the proximal humerus account for $4 \%$ to $10 \%$ of all fractures; the most common trauma mechanism is a fall from the patient's own height. Fractures of proximal humerus associated with dislocation in convulsive disorders pose a management challenge.

Fixation techniques described in the literature are myriad and none is ideal for all cases [2-9]. The majority of patients with this fracture are young and active who require a good functional outcome. Early reduction of the dislocation and stable fixation of the fractures offers the best chance for an acceptable outcome. A wide variety of treatment modalities have been used in the past with various surgical implants developed over the years. The management is more challenging in cases of locked fracture dislocations since closed reduction often fails to achieve reduction and results in a delay in the management. Improved outcome following surgical fixation by locking plates is attributed to the angular stability of the screws locking in the plate and their three-dimensional distribution in the humeral head with purchase in different fracture pieces. The Proximal humeral internal locking system (PHILOS) plate fixation provides greater angular stability than do conventional implants [2-6]. In stable 
two-part fractures the use of cancellous screws or tension band techniques is an option. In elderly patients who are unfit for total shoulder replacement or don't consent for ORIF the use of percutaneous $\mathrm{K}$-wires is a reasonable option. In proximal humerus fractures a good functional outcome with early joint mobilization and rigid fixation of the fracture is key.

In the literature review no definite outcome scoring system is described for proximal humerus fractures with dislocation hence the author has described a simple and reproducible tool that can be expanded for use in other proximal humerus fractures [10-14]. The commonly used shoulder outcome score including the constant score, the disability of the arm, shoulder and hand (DASH), and Oxford score don't specifically address the functional outcomes in patients treated for complex shoulder fracture dislocations. The proposed ESS is a simple assessment tool used during outpatient follow-up but needs further validation.

\section{Materials and Methods}

We reviewed ten patients admitted to various private hospitals in Nairobi county due to proximal humeral head fracture associated with dislocations after a convulsive episode between November 2015 and May 2019. All the patients were seen and managed by the author. Medical data and imaging studies (radiography and CT) of the patients were reviewed for analysis. All patients were followed postoperatively for a minimum period of 12 months.

The consent for surgery and anaesthesia were taken after a clear explanation. On the initial review at casualty a careful history was taken about age, sex, details of injury, duration. Patients were evaluated for associated medical problems and associated convulsions. Preoperative Shoulder Antero posterior, Lateral and Axial X rays were taken (Figure 1A). A CT scan with 3D reconstruction or Magnetic Resonance Scanning (MRI) was done in all cases before surgery (Figure 1B). The patients were then booked for emergency surgery on the next available theatre slot.

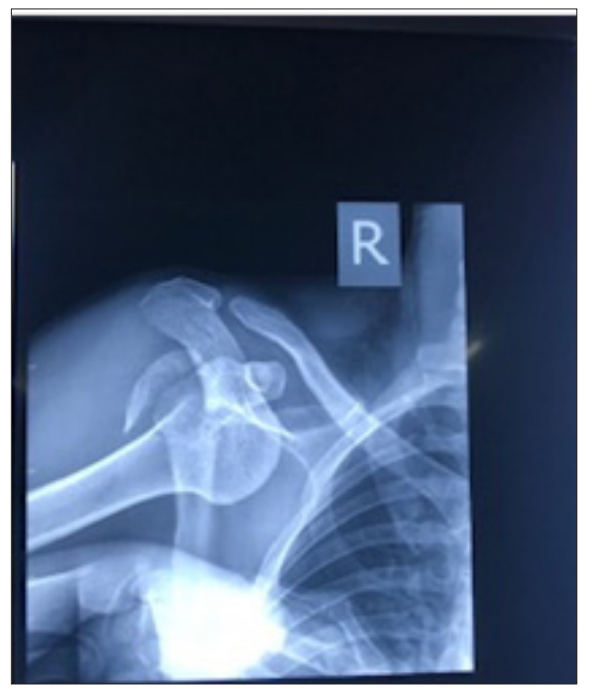

Figure 1A: AP $\mathrm{X}$ ray showing anterior fracture dislocation (Case 2).

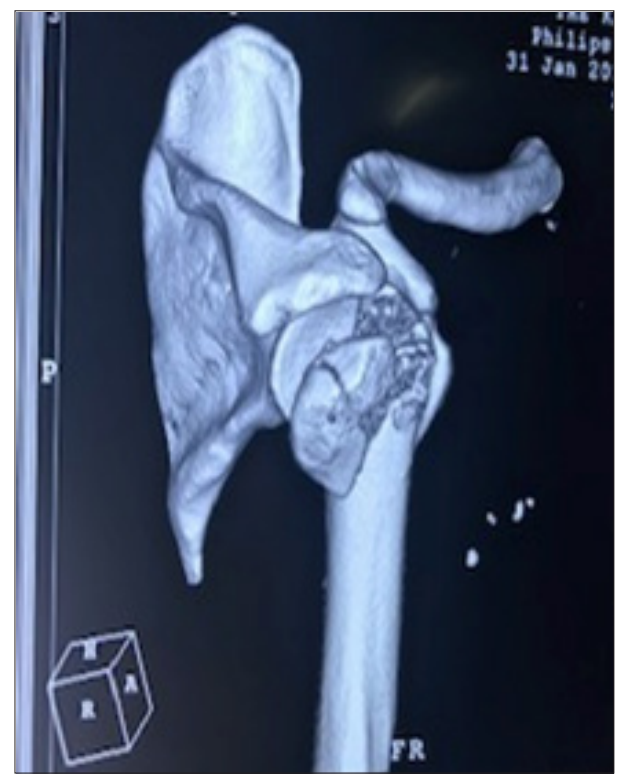

Figure 1B: CT Scan showing anterior fracture dislocation (Case 2).

General anaesthesia was used for all the patients in the beach chair position. Closed reduction was then done and confirmed by image intensifier, then fracture fixed by percutaneous $\mathrm{K}$ wires in three patients. In six patients open surgery and internal fixation (ORIF) was performed after failing to achieve acceptable reduction or the dislocation was irreducible. In the six cases surgery was performed through the delto-pectoral approach, the fracture site exposed, reduction of the fracture fragments done with minimal soft tissue dissection. The anatomical relationship between humeral head and greater tuberosity was restored and fixed temporarily with $\mathrm{K}$ wires. The fragments were indirectly reduced with the help of traction sutures, which were placed in the insertions of rotator cuff tendons. When acceptable reduction was obtained K-wires, cancellous screws or a PHILOS plate was used to maintain the reduction. Fluoroscopic images were taken to confirm satisfactory fracture reduction, plate positioning and proper length of screws in the humeral head. In one case (13-year-old/F) the preoperative MRI confirmed a large Anterior Labral Periosteal Sleeve Avulsion (ALPSA) lesion and after closed reduction arthroscopic repair was done and the greater tuberosity fragment fixed using cannulated screws. In all cases full range of motion of shoulder was checked on the operative table and impingement ruled out.

After surgery the shoulder was immobilized in a shoulder immobilizer with a swath and sling. Immediate post-operative check radiographs were taken to determine the alignment of the bone and maintenance of reduction. Depending on the pain tolerance and stability of the fixation, pendulum exercises were begun as soon as possible, active range of motion started at 2-4 weeks postoperatively. At the sixth week use of the immobilizer was discontinued and free shoulder motion allowed. Between the sixth and eighth week-full range of motion with active exercises was started at the physiotherapy department. Every four weeks the 
progress of healing was assessed both clinically and radiologicaly in the outpatient clinics. Outcomes were categorized based on a proposed outcome score (Everisto Scoring System-ESS).

The ESS uses four parameters to categorize the outcome after three months to six months of follow up. The first parameter is the shoulder active range of motion in the key muscle groups (forward flexion, abduction, internal and external rotation) as a percentage of the normal measured using a goniometer. Secondly it assesses the pain score on a visual analogue scale and the need for analgesics on a need basis (PRN-Pro re nata) or constantly on a daily basis. The last parameter assesses the radiological outcomes in terms of fracture healing, malunion and need for further surgery such as shoulder replacement of rotator cuff repair. An aggregate score is given with the least being 4 and maximum of 12 (Table 1).

Table 1:

\begin{tabular}{|c|c|c|c|c|c|}
\hline Parameter & $\begin{array}{c}\text { Shoulder Range of Motion } \\
\text { at 3 -6 Months }\end{array}$ & $\begin{array}{c}\text { Pain Score on Visual } \\
\text { Analogue Score (0-10)/ }\end{array}$ & Analgesic Use & Need for Further Surgery/ Complications & Score \\
\hline & $>70 \%$ of normal & Pains score $0-3$ & PRN & NONE & 3 \\
\hline & $50-70 \%$ of normal & Pain score 3-5 & PRN & NONE & 2 \\
\hline & $<50 \%$ of normal & Pain score $>5$ & DAILY & YES e.g shoulder replacement & 1 \\
\hline
\end{tabular}

\section{Analysis}

a) Excellent: total score of 10-12

b) Good: total score of 7-9 c) Poor: total score of 6 or less

Ethical clearance approval for the study was requested and obtained from the Institutional Ethics Committee.

\section{Results}

\section{Patient data summary}

Table 2

\begin{tabular}{|c|c|c|c|c|c|}
\hline Patient /Sex/Age & Fracture Type & Associated Injury & Comorbidity & Management & Outcome \\
\hline Case $1 \mathrm{M} / 44 \mathrm{Y}$ & Left 3-part fracture & Posterior dislocation & First convulsion & $\begin{array}{l}\text { ORIF/ Mc Laughlins proce- } \\
\text { dure }\end{array}$ & Good \\
\hline Case $2 \mathrm{M} / 34 \mathrm{Y}$ & Right 2 part & Anterior dislocation & Stiffmans Persons syndrome & ORIF with screws & Excellent \\
\hline Case $3 \mathrm{M} / 38 \mathrm{Y}$ & Left 4 part communited & Posterior dislocation & First convulsion & ORIF with PHILOS plate & Good \\
\hline Case $4 \mathrm{M} / 21 \mathrm{Y}$ & Left 2 part & Posterior dislocation & $\begin{array}{c}\text { Delirium tremens due to alco- } \\
\text { hol withdrawal }\end{array}$ & ORIF with PHILOS plate & Excellent \\
\hline Case 5 M/43Y & Right 4 part & Anterior dislocation & First convulsion & $\begin{array}{l}\text { ORIF with K wires \& Philos } \\
\text { plating }\end{array}$ & Good \\
\hline Case 6 F/81 Y & $\begin{array}{l}4 \text { part severely commu- } \\
\text { nited }\end{array}$ & Anterior dislocation & $\begin{array}{l}\text { Osteoporosis, First convulsion } \\
\text { due to brain tumour }\end{array}$ & $\begin{array}{c}\text { Closed reduction \& percuta- } \\
\text { neous K wires }\end{array}$ & Poor \\
\hline Case $7 \mathrm{M} / 50 \mathrm{Y}$ & 2 part & Anterior dislocation & First convulsion & Closed reduction \& arm sling & Excellent \\
\hline Case $8 \mathrm{M} / 28 \mathrm{Y}$ & 3 part & Anterior dislocation & Third convulsion & ORIF with screws & Excellent \\
\hline Case $9 \mathrm{~F} / 22 \mathrm{Y}$ & 3 part & Posterior dislocation & Ecclampsia & Closed reduction \& K wires & Poor \\
\hline Case $10 \mathrm{~F} / 13 \mathrm{Y}$ & 2 part & Anterior dislocation & Third convulsion & $\begin{array}{l}\text { Arthroscopic repair of ALPSA } \\
\text { lesion and cannulated screws }\end{array}$ & Excellent \\
\hline
\end{tabular}

(Table 2) Three patients were female and seven were male. Nine patients were of the African race and one Asian. The average age at the time of injury was 37.4 (13-81) years. The radiological classification according to Neer's classification was 40\% 2-part, $30 \%$ part and 30\% 4-part fractures. Excellent results were achieved in all 2-part fractures and one 3-part fracture.

Most of the fractures were due to a first-time convulsive disorder of unknown aetiology. The only known aetiologies were that of 22-year-old female with ecclampsia, 21-year-old male with delirium tremens due to alcohol withdrawal, 81-year-old with brain tumour and the case of Stiffmans Syndrome in a 33-year-old man. Immediate closed reduction of the fracture-dislocation of the shoulder was attempted under general anesthesia followed by open reduction and internal fixation in six patients (Figures 2-5). Closed reduction and percutaneous $\mathrm{K}$ wire were done in two patients and in one patient with a 2-part fracture closed reduction was followed by immobilization in arm sling without any fixation. The average time elapsed from injury to successful closed reduction was 8 hours except for case 1 and 3 who presented after more than three days. In case one the patient presented one week after failed attempted closed reduction in another hospital because it was a locked 
dislocation. He underwent open surgery to reduce the dislocation and a modified Mc Laughlins procedure-using suture anchors with transfer of the subscapularis tendon transfer. In case 3 the 38-yearold presented 3 days after admission and failed closed reduction at another hospital. His CT Scans revealed a severely communited 4-part fracture with a locked posterior dislocation (Figure 2A). He underwent open reduction and internal fixation using a PHILOS plate and several sutures to repair the supraspinatus and subscapularis tendons into position. The 81-year-old with a firsttime convulsion due to brain tumour was managed by closed reduction with percutaneous pinning with $\mathrm{K}$ wires and developed avascular necrosis (AVN) of the humeral head and a poor functional outcome Figure 6A, 6B \& 6C. The 13-year-old with right shoulder fracture dislocation had an unstable dislocation that had been reduced in another hospital and re-dislocated within one week. Her shoulder X rays revealed a 2-part anterior fracture dislocation, but the MRI revealed a large ALPSA lesion as well. She was managed by arthroscopic repair of the ALPSA lesion after closed reduction and percutaneous pinning of the greater trochanter followed by cannulated screws.

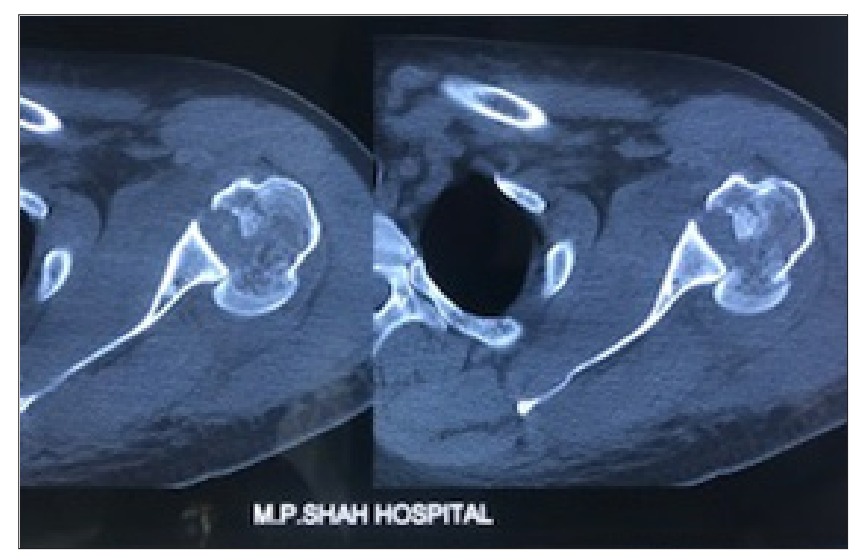

Figure 2A: Pre-operative CT scan (Case 3).

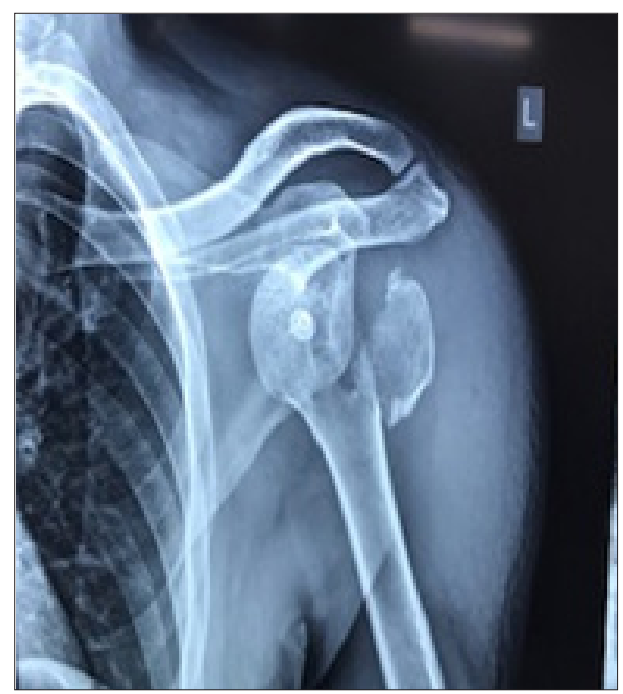

Figure 2B: $X$ ray of the Left shoulder showing a locked posterior fracture /dislocation (Case 3).

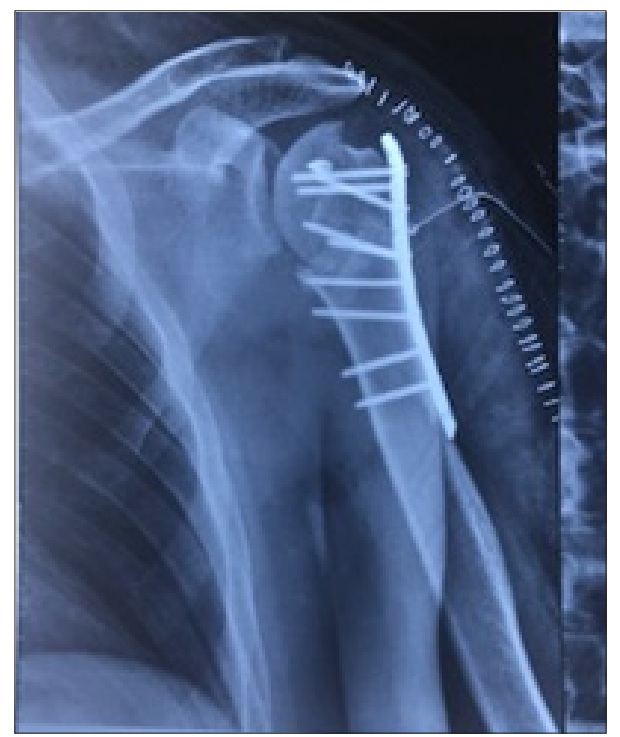

Figure 2C: Immediate post-operative picture (Case 3).

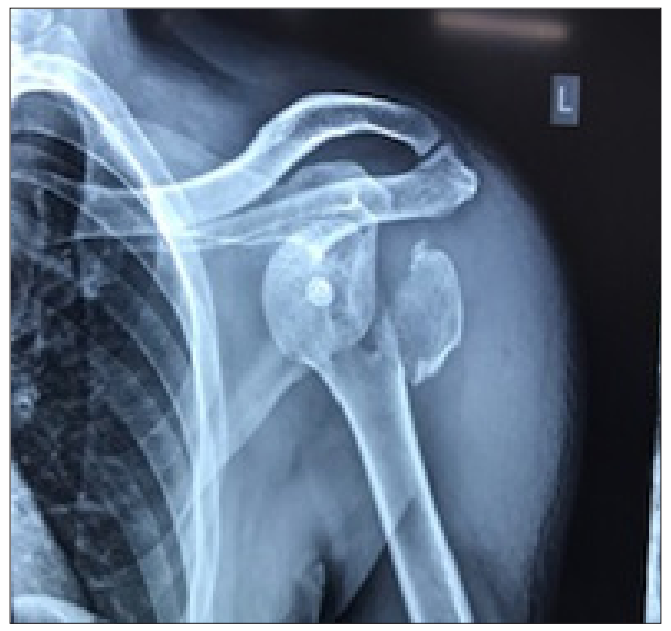

Figure 3A: $X$ ray of the Left shoulder showing a posterior fracture / dislocation (Case 2).

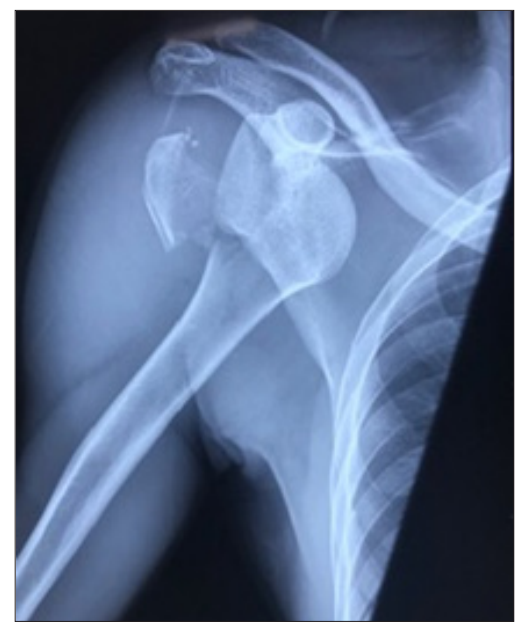

Figure 4A: Pre op anterior dislocation (Case 8). 


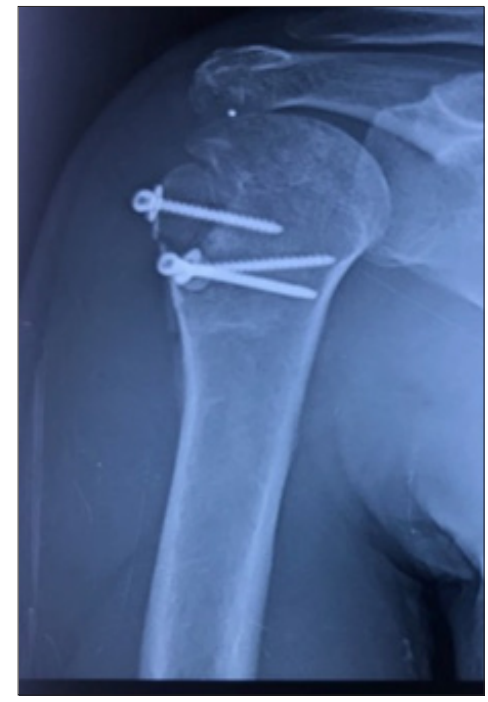

Figure 4B: Postoperative at 4 weeks (Case 8 ).

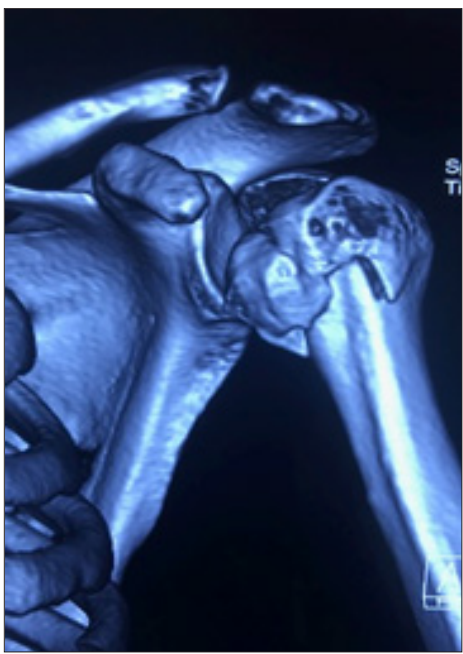

Figure 5A: Pre-operative CT scan (Case 5).

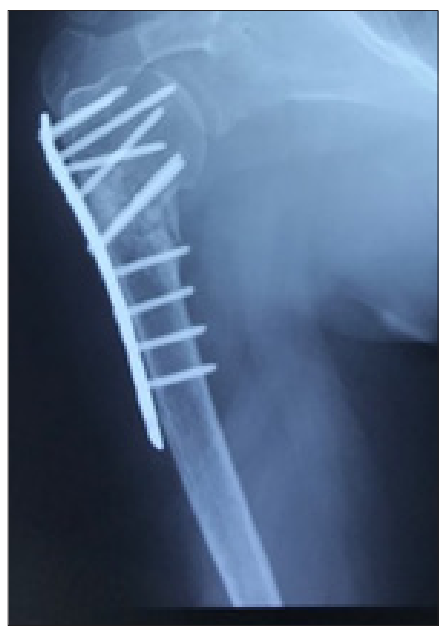

Figure 5B: Postoperative $\mathrm{X}$ ray at 6 months (Case 5).

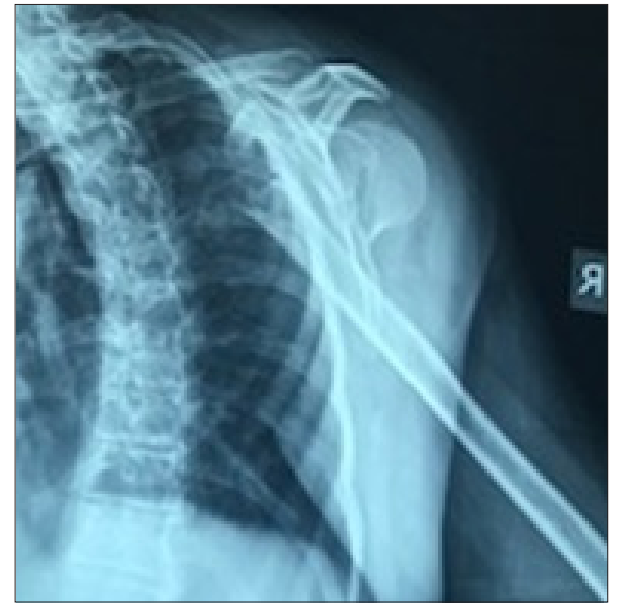

Figure 6A: Pre op X-ray 81-year-old with shoulder fracture dislocation (Case 6).

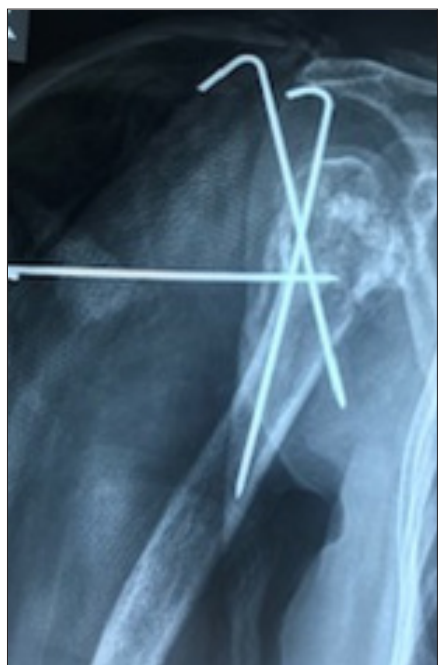

Figure 6B: Intra op X-ray 81-year-old with shoulder fracture dislocation (Case 6).

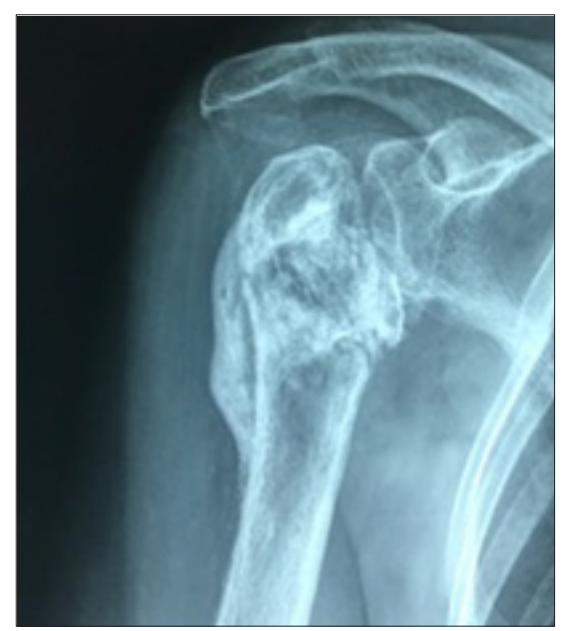

Figure 6C: 81 -year-old at six months post op X-ray 81 year old with AVN (Case 6). 


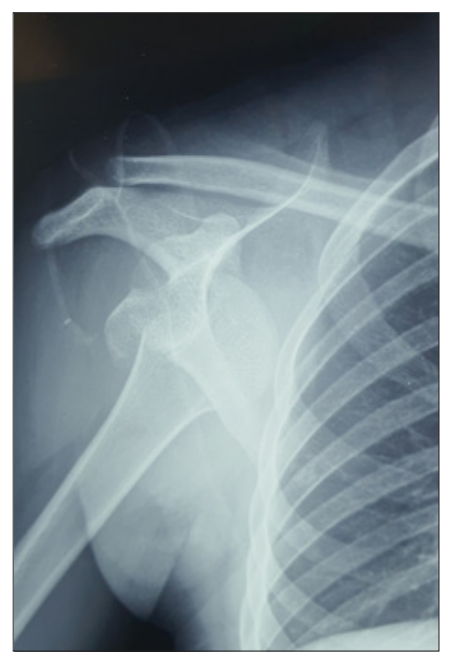

Figure 7A: Pre op X-rays of 13-year-old with fracture dislocation after tonic clonic seizure.

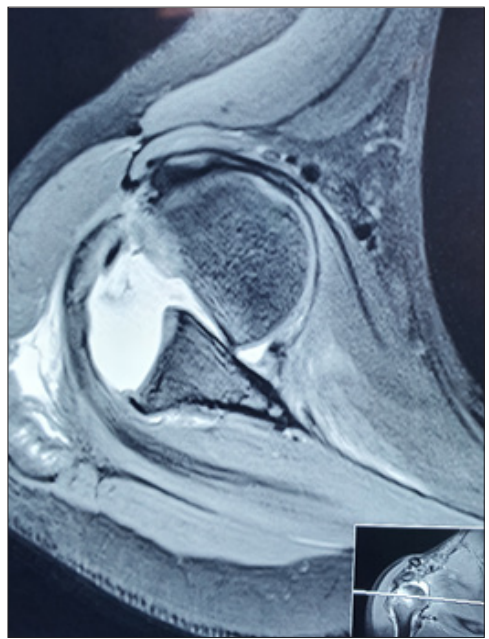

Figure 7B: Pre-operative MRI Scan of the 13 year old showing an ALPSA lesion.

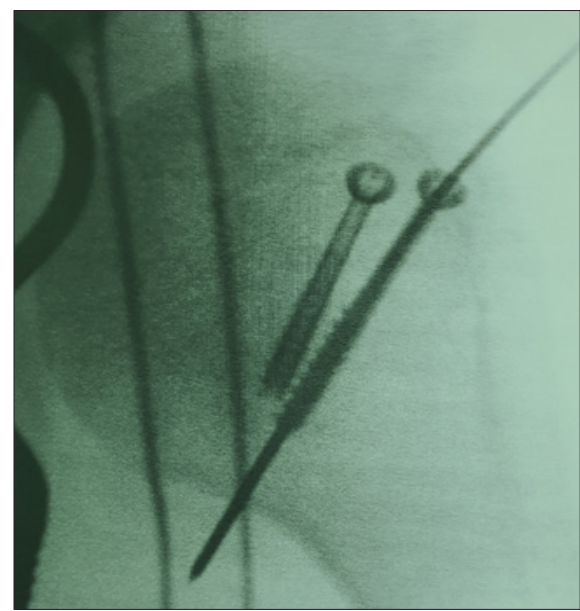

Figure 7C: Intra operative image of the greater tuberosity fracture in 7A fixed using cannulated screws.
Based on the proposed Everisto Scoring System (ESS) excellent results were recorded in 50\%, good result in 33\% and two patients had a poor outcome (20\%) (Figure 7).

\section{Discussion}

First time convulsions associated with fracture dislocations of the shoulder present as complex injuries that require thorough preoperative planning and good surgical care for ideal outcomes. Few selected cases with 2-part fractures can be managed by closed reduction and arm sling immobilization.

The mechanism for a posterior dislocation with fracture of the shoulder during a seizure as described by Shaw in the 70s remains valid to date [15]. The position of the shoulder during a seizure is described as one of adduction, internal rotation and flexion. In that position the humeral head is drawn cranially and posteriorly against the acromion and medially against the glenoid fossa by generalized contraction of the shoulder muscles. The infraspinatus, teres minor, deltoid, latissimus dorsi and teres major provide sufficient power to dislocate the humerus posteriorly. When a seizure has ended the head of the humerus is behind the glenoid fossa, often with a large impression fracture of the head just medially to the lesser tubercle near the anatomical neck of the humerus (reversed Hill-Sachs lesion). With an ongoing seizure the anatomical neck of the humerus will be drawn to the rim of the glenoid fossa and becomes impacted and is eventually fractured. The subscapular and infraspinatus muscles draw the two fragments from each other, resulting in the typical 'four-part fracture' according to Neer [16]. Further comminution can occur by forceful contraction of the triceps, the coracobrachialis, the biceps and the deltoid muscles, which will pull the head of the humerus cranially to the acromion. This mechanism is likely to be the case in the first and second patient presented in this case series.

The assessment of these injuries needs at least 3 basic radiographs and CT Scanning for a complete 360-degree evaluation of the relationship of the humeral head, tuberosities and the shaft. Cases of posterior fracture dislocation can easily be missed on standard X rays of the shoulder. In a study by Hawkins only $50 \%$ of posterior dislocations were recognized with a standard AP and lateral X-ray. With the addition of axillary X-rays, the diagnosis is usually more clearly made in most cases [6]. However, it is very difficult to take an axillary X-ray in a patient with pain and the inability to abduct the shoulder immediately after the injury. A CT scan is therefore key in making the diagnosis of a posterior fracture dislocation and in planning of the subsequent management especially surgery. In cases of recurrent instability in convulsive disorders the MRI scan provides important information about the associated labral and capsular lesions that may need to be addressed for good clinical outcomes.

\section{Operative management options}

The primary aim of operative fixation is to restore function to a reasonable level in comparison to the preinjury state. In order for this outcome to occur, congruency must be restored between 
humeral head and its shaft, along with anatomical reduction of the tuberosities and their related cuff attachments. Sometimes a combination of surgical options is necessary and the use of additional suture anchors and $\mathrm{K}$ wire maybe necessary especially in four-part fractures as in case 1 and 3 of this series. Infection, non-union and metalwork failure are the possible complications associated with operative intervention.

\section{Closed reduction and percutaneous fixation}

Closed reduction and percutaneous fixation, as a management option is ideal for fractures, which have a high chance of union after reduction. These include fractures with a stable configuration, which exhibit minimal displacement (less than 30 degrees of varus/ valgus angulation of the diaphyseal shaft in relation to the humeral head).

The obvious advantage of this technique is minimal soft tissue dissection, shorter operative time in patients who may have high anaesthetic risks such as the 81-year-old in this series who also had a brain tumour. Closed reduction and percutaneous fixation reduce the risk of avascular necrosis, non- union, blood loss and infection in comparison to open reduction and internal fixation. It also allows for earlier initiation of post-operative physiotherapy and early resumption of shoulder function due to minimal scar tissue formation [17]. The fracture is reduced under image guidance and held by the use of either Kirschner $(\mathrm{K})$ wires or cannulated srews [17-20]. During the procedure special care is taken to avoid damage to keys structures at risk such as the axillary nerve, cephalic vein, long head of biceps tendon and posterior circumflex humeral artery has been previously documented [20].

\section{Open reduction internal fixation}

In case of surgery the delto-pectoral approach provides an excellent exposure for proper reduction and internal fixation. Exposure for comminuted fractures, particularly those including the posterior aspect of the humeral head, can also be approached using the extended transdeltoid approach. Plate and screw design, with multi-directional locking options have been confirmed to withstand extreme pull out forces and hence low failure rates in management of proximal humerus fractures [21-24]. The most studied and report being the PHILOS plating system [22]. Anatomical reduction has to be confirmed in theatre by fluoroscopy. Various studies have reported good outcomes using plate and screws especially the PHILOS plating system in management of 3 and 4-part proximal humerus fractures [21-27].

Proximal humerus intramedullary nailing is mostly suited to 2- and 3-part surgical neck fractures. However, in 3 and 4 part fractures the results of nailing are significantly poor [28-30]. In a patient with fracture dislocation it's the authors view that closed nailing wouldn't be ideal due to the difficulty of achieving a good reduction and fracture alignment with additional trauma to the humeral head.
However, in elderly patients with four-part fracture associated with osteoporosis the use of a joint replacement prosthesis is a better option. Neer endorsed the use of arthroplasty for 3- or 4-part fractures in response to the high rates of non-union and AVN seen with earlier plating designs [31]. The recent advances in plate fixation methods and understanding of the fracture pathology have significantly reduced the rates of the complications, thus lessening the need for head replacing surgery especially in young patients. The management of the convulsive disorder as well is critical for good long-term outcomes.

\section{Arthroscopic management}

Shoulder arthroscopy is useful in cases where recurrent dislocation is associated with gross instability. However, in patient with gross anterior instability associated with fracture dislocation arthroscopic fixation of the labral and capsular lesions provides an excellent result.

\section{Outcome assessment}

Of the many upper limb outcome assessment sores non-has been specifically tailored for use in patients with shoulder fractures associated with dislocation. It's to this end the author was motived to design and use the ESS for this study.

The disability of the arm, shoulder and hand (DASH) questionnaire being the most widely used upper-extremity specific outcome measure was introduced by the American Academy of Orthopedic Surgeons in collaboration with a number of other organizations $[10,32]$. The rationale behind the use of one outcome measure for different upper extremity disorders is that the upper extremity is a functional unit. However, the DASH has been found to be suitable mainly as measure of disability in a variety of upper limb conditions. The constant score evaluates the range of motion, strength but fails to address the aspect of clinical and radiological complications, which is relevant in a fracture and dislocation scenario being addressed in this study. Unlike DASH the ESS assesses both disability and functional recovery after a sudden traumatic event that causes immediate shoulder disability in a previously normal shoulder.

\section{Study limitations}

This study has the limitation of small numbers associated with case series and the lack of a control group. It's however noteworthy that most reported cases in the literature are from case reports and small studies due to the rarity of these injuries.

\section{Conclusion}

The management of fracture dislocation of the humerus in patients with convulsive disorders should always aim for anatomic reduction of the fragments with minimal soft tissue injury. Sometimes closed reduction is enough, but in the presence of large fragments, the fracture- dislocation is better treated by ORIF 
for restoration of a good range of motion. In cases of recurrent dislocation with significant soft tissue lesion the arthroscopic management offers an excellent option. The use of ESS outcome score has a promisisng future in follow up of patients managed for shoulder fracture dislocations.

\section{References}

1. Szyluk KJ, Jasiński A, Mielnik M, Koczy B (2016) Incidence of posttraumatic shoulder dislocation in Poland. Med Sci Monit 22: 39673974.

2. Paavolainen P, Bjorkenheim JM, Slatis P, Paukku P (1983) Operative treatment of severe proximal humeral fractures. Acta Orthop Scand 54(3): 374-379.

3. Koukakis A, Apostolou CD, Taneja T, Korres DS, Amini A (2006) Fixation of proximal humerus fractures using the PHILOS plate: early experience. Clin Orthop Relat Res 442: 115-120.

4. Fazal MA, Haddad FS (2009) PHILOS plate fixation for displaced proximal humeral fractures. J Orth Surg 17(1): 15-18.

5. Egol KA, Ong CC, Walsh M, Jazrawi LM, Tejwani NC, et al. (2008) Early complication of proximal humerus fractures treated with locked plates. J orthop trauma 22(3): 159-164.

6. Brunner F, Sommer C, Bahrs C, Heuwinkel R, Hafner C, et al. (2009) Open reduction and internal fixation of proximal humerus fractures using a proximal humeral locked plate: A prospective multicenter analysis. J Orthop Trauma 23(3): 163-172.

7. Lous Bigiliani U, Charles Rockwood, Frederick A (1990) Fractures of proximal humerus Chapter 9 the shoulder. In Rockwood CA, Matsen, W.B. Saunders, Philadelphia, USA, 1: 278-334.

8. Kumar C, Gupta AK, Nath R, Ahmad J (2013) Open reduction and locking plate fixation of displaced proximal humerus fractures. Indian J Orthop 47(2): 156-160.

9. Helmy N, Hintermann B (2006) New trends in the treatment of proximal humerus fractures. Clin Orthop Relat Res 442: 100-108.

10. Kirkley A, Griffin S, Alvarez C (2003) The development and evaluation of a disease-specific quality of life measurement tool for rotator cuff disease: The Western Ontario Rotator Cuff Index (WORC). Clinical Journal of Sport Medicine 13(2): 84-92.

11. Rowe CR, Patel D, Southmard WW (1977) The Bankart procedure a study of late results. Journal of Bone and Joint Surgery 59: 122.

12. Amstutz HC, Sew Hoy AL, Clarke IC (1981) UCLA anatomic total shoulder arthroplasty. Clinical Orthopaedics 155: 7-20.

13. Roach KE, Budiman-Mak E, Songsiridej M (1991) Development of a shoulder pain and disability index. Arthritis Care \& Research 4(4): 143149.

14. Richards RR, An KN, Bigliani LU (1994) A standardized method for the assessment of shoulder function. Journal of Shoulder and Elbow Surgery 3(6): 347-352.

15. Shaw JL (1971) Bilateral posterior fracture-dislocation of the shoulder and other trauma caused by convulsive seizures. Journal of Bone and Joint Surgery 53(7): 1437-1440.
16. Hawkins RJ, Neer CS, Pianta RM, Mendoza FX (1987) Locked posterior dislocation of the shoulder. Journal of Bone and Joint Surgery 69(1): 9-18.

17. Keener JD, Parsons BO, Flatow EL (2007) Outcomes after percutaneous reduction and fixation of proximal humeral fractures. J Shoulder Elbow Surg 16(3): 330-338.

18. Jaberg H, Warner JJ, Jakob RP (1992) Percutaneous stabilization of unstable fractures of the humerus. J Bone Joint Surg Am 74(4): 508-515.

19. Resch H, Povacz P, Frohlich R, Wambacher M (1997) Percutaneous fixation of three- and four-part fractures of the proximal humerus. J Bone Joint Surg Br 79(2): 295-300.

20. Rowles DJ, McGrory JE (2001) Percutaneous pinning of the proximal part of the humerus. An anatomic study. J Bone Joint Surg Am 83(11): 1695-1699.

21. Koukakis A, Apostolou CD, Taneja T, Korres DS, Amini A (2006) Fixation of proximal humerus fractures using the PHILOS plate: early experience. Clin Orthop Relat Res 442: 115-120.

22. Bjorkenheim JM, Pajarinen J, Savolainen V (2004) Internal fixation of proximal humeral fractures with a locking compression plate: a retrospective evaluation of 72 patients followed for a minimum of 1 year. Acta Orthop Scand 75(6): 741-745.

23. Kiliç B, Uysal M, Cinar BM, Ozkoç G, Demirörs H, et al. (2008) Early results of treatment of proximal humerus fractures with the PHILOS locking plate. Acta Orthop Traumatol Turc 42(3): 149-153.

24. Kristiansen B, Christensen SW (1986) Plate fixation of proximal humeral fractures. Acta Orthop Scand 57(4): 320-323.

25. Wijgman AJ, Roolker W, Patt TW, Raaymakers EL, Marti RK (2002) Open reduction and internal fixation of three- and four-part fractures of the proximal part of the humerus. J Bone Joint Surg Am 84(11): 1919-1925.

26. Thyagarajan DS, Haridas SJ, Jones D, Dent C, Evans R, et al. (2009) Functional outcome following proximal humeral interlocking system plating for displaced proximal humeral fractures. Int J Shoulder Surg 3(3): 57-62.

27. Esser RD (1994) Treatment of three- and four-part fractures of the proximal humerus with a modified cloverleaf plate. J Orthop Trauma $8(1): 15-22$.

28. Adedapo AO, Ikpeme JO (2001) The results of internal fixation of threeand four-part proximal humeral fractures with the Polarus nail. Injury 32(2): $115-121$

29. Agel J, Jones CB, Sanzone AG, Camuso M, Henley MB (2004) Treatment of proximal humeral fractures with Polarus nail fixation. J Shoulder Elbow Surg 13(2): 191-195.

30. Lin J, Hou SM, Hang YS (1998) Locked nailing for displaced surgical neck fractures of the humerus. J Trauma 45(6): 1051-1057.

31. Neer $2^{\text {nd }} C S$ (1970) Displaced proximal humeral fractures. II. Treatment of three-part and four-part displacement. J Bone Joint Surg Am 52(6): 1090-1103.

32. Kirkley A, Griffin S, McLintock H (1998) The development and evaluation of a disease-specific quality of life measurement tool for shoulder instability: The Western Ontario Shoulder Instability Index (WOSI). American Journal of Sports Medicine 26(6): 764-772. 